\title{
The use of convalescent plasma, dexamethasone and remdesivir in a renal transplant patient infected with COVID-19
}

\author{
Sheena Hannabas FNP-C, MSN, Gregory Hannabas MD, MPH, MPA, Camilo Pena MD
}

\begin{abstract}
Background: Immunocompromised patients, such as renal transplant recipients, are a high-risk population for coronavirus disease 2019 (COVID-19) infection and complications. The evidence to support specific treatment of COVID-19 in this group of patients remains very limited. We present the first case in West Texas of a renal transplant patient who received combined therapy with convalescent plasma, dexamethasone, and remdesivir for the treatment of COVID-19.

Case summary: We report a female patient who received a deceased donor kidney transplant approximately 2 years prior. She was admitted to our institution with respiratory distress with symptomatic COVID-19 infection. Her baseline renal allograft function per serum creatinine was $0.9 \mathrm{mg} / \mathrm{dL}$, and she was on maintenance immunosuppression with tacrolimus, mycophenolate mofetil, and prednisone. Throughout her hospitalization, her mycophenolate mofetil was maintained, the prednisone was switched for dexamethasone, and her tacrolimus dosage required multiple adjustments secondary to interactions with the azithromycin used to treat an atypical pneumonia upon admission to the hospital. The patient eventually required supplemental oxygen with a venti-mask at $50 \% \mathrm{FiO}_{2}$ and transfer to the medical intensive care unit. She received convalescent plasma from a COVID-19 recovered patient, in addition to dexamethasone and then remdesivir for 5 days, with clinical improvement. She was discharged on $3 \mathrm{~L}$ per minute supplemental oxygen by nasal cannula from the hospital on day 17 of hospitalization.

Conclusion: This renal transplant patient in West Texas with symptomatic COVID-19 infection was treated with convalescent plasma, remdesivir, and dexamethasone with a good outcome. This case also shows the common and often missed drug interactions between tacrolimus and azithromycin and describes a safe way of lowering immunosuppression without compromising renal allograft function.
\end{abstract}

Keywords: COVID-19, coronavirus, renal transplant, immunosuppression, convalescent plasma, dexamethasone, remdesivir, tacrolimus, mycophenolate mofetil

\section{INTRODUCTION}

Convalescent plasma has become a therapeutic option during the coronavirus disease 2019 (COVID19) pandemic. However, evidence remains limited and

Corresponding author: Sheena Hannabas Contact Information: Sheena.Hwannabas@ttuhsc.edu DOI: $10.12746 /$ swrccc.v8i36.753 controversial when considering the use of this therapeutic modality. Furthermore, the available evidence still lacks definitive outcomes. One study published in The Journal of the American Medical Association found that patients with severe symptoms associated with COVID19 did not show statistically significant improvement in 28-day mortality or discharge with convalescent plasma therapy. However, the group that received convalescent plasma did have a faster negative conversion rate of viral PCR compared to the control group. ${ }^{1}$ Furthermore, 
Table 1. Recommendations from Transplant Organizations Regarding Immunosuppression Management

\begin{tabular}{|c|c|c|}
\hline Organization & Recommendation & Date \\
\hline $\begin{array}{l}\text { International Society for Heart } \\
\text { and Lung Transplantation }\end{array}$ & $\begin{array}{l}\text { "All prior disease-specific therapy or immunosuppression should be } \\
\text { continued unless otherwise instructed"5 }\end{array}$ & $08 / 19 / 2020$ \\
\hline $\begin{array}{l}\text { Canadian Society of } \\
\text { Transplantation and The } \\
\text { Transplantation Society of } \\
\text { Canada }\end{array}$ & $\begin{array}{l}\text { "Changes in immunosuppression are also not well studied in the } \\
\text { transplant populations. Calibration of dose reduction has to balance } \\
\text { consequences of rejection (i.e. easier to do with kidney transplants than } \\
\text { heart transplantation)." }\end{array}$ & $06 / 08 / 2020$ \\
\hline $\begin{array}{l}\text { American Society of } \\
\text { Transplantation }\end{array}$ & $\begin{array}{l}\text { "The impact of immunosuppression on COVID-19 is not currently } \\
\text { known but decreasing immunosuppression should be considered for } \\
\text { infected recipients who have not had recent rejection episodes. Many } \\
\text { providers have decreased or discontinued cell cycle inhibitors or reduced } \\
\text { calcineurin inhibitor levels, but comparative data regarding these } \\
\text { interventions are not yet available."? }\end{array}$ & $06 / 18 / 2020$ \\
\hline $\begin{array}{l}\text { Organ Procurement and } \\
\text { Transplantation Network }\end{array}$ & No recommendations regarding immunosuppression management. ${ }^{8}$ & $02 / 28 / 2020$ \\
\hline $\begin{array}{l}\text { European Renal Association/ } \\
\text { European Dialysis and } \\
\text { Transplantation Association }\end{array}$ & $\begin{array}{l}\text { "-Asymptomatic patients: No change of immunosuppression. } \\
\text {-Mild disease (only mild upper respiratory and/or gastrointestinal } \\
\text { symptoms, oxygen saturation in room air is }>95 \text { ): Stop mycophenolate/ } \\
\text { azathioprine/mammalian target of rapamacyn inhibitor. Consider } \\
\text { calcineurin inhibitor dose if there is no clear improvement over the first } \\
3-5 \text { days. } \\
\text {-Severe COVID-19 pneumonia (oxygen saturation }<94 \% \text { in room air, } \\
\text { respiratory rate } \geq 30 / \text { min), unstable or deteriorating course (with or } \\
\text { without mechanical ventilation): Discontinue all IS drugs, increase/ } \\
\text { start steroids at } 15-25 \mathrm{mg} / \text { day (or higher according to local practice). } \\
\text { Carefully consider to continue with low dose calcineurin inhibitor in } \\
\text { patients with higher risk of rejection."9 }\end{array}$ & $06 / 04 / 2020$ \\
\hline $\begin{array}{l}\text { British Transplantation } \\
\text { Society }\end{array}$ & $\begin{array}{l}\text { "Levels of immunosuppression should be reviewed but generalised } \\
\text { immunosuppression reduction that may jeopardise organ function is not } \\
\text { recommended"10 }\end{array}$ & $08 / 14 / 2020$ \\
\hline
\end{tabular}

it is important to note that this study was terminated early due to decreased COVID-19 numbers in Wuhan, China, at the time of the investigation. Evidence to support convalescent plasma in renal transplant patients is also lacking and remains controversial at this time. Jiang and colleagues recently published a case report that supported the use of convalescent plasma in renal transplant patients. This report also suggested that immunosuppression agents must be adjusted to manage infection vs. rejection. ${ }^{2}$ Another case report published in American Journal of Transplantation showed that treatment regimens for COVID-19 in renal transplant patients should include reduced immunosuppression and low dose methylprednisolone-based therapy. ${ }^{3}$ New evidence shows remdesivir may shorten recovery in patients with COVID-19 and respiratory infection. ${ }^{4}$ For patients with special conditions, such as renal transplantation, evidence to support treatment of COVID-19 remains very limited (Table 1). ${ }^{5-10}$ For this reason, we report the first case in West Texas of a renal transplant patient who received convalescent plasma, dexamethasone, and remdesivir for treatment of COVID-19, 
recovered, and was successfully discharged home with limited need for oxygen support.

\section{CASE REPORT}

A 62-year-old woman with a past medical history of diabetes mellitus type 2, hypertension, coronary artery disease status-post CABG seven years ago, hypothyroidism, and renal failure status-post deceased donor kidney transplantation approximately 2 years prior to admission. Prior to her transplantation, the patient was on peritoneal dialysis for five years. Her serum creatinine was $0.9 \mathrm{mg} / \mathrm{dL}$ at baseline before presentation to the hospital for symptoms related to COVID-19 infection. She was on maintenance immunosuppression with tacrolimus, mycophenolate mofetil, and prednisone prior to admission.

On day 1 , the patient presented to the emergency department (ED) for symptoms of fever, cough, dyspnea, chest pain, and nausea that had progressively worsened over the previous four days before admission. She had been tested for COVID-19 at an outlying community clinic the day prior and was found to be positive. The patient had been exposed to the virus by her son who also tested positive prior to her diagnosis. Of note, she also tested positive for a Streptococcal infection four days prior to admission and was being treated with amoxicillin.

Initial presentation vital signs revealed a temperature of $100.9^{\circ} \mathrm{F}$, blood pressure $142 / 71 \mathrm{mmHg}$, heart rate 66 beats per minute, respiratory rate 24 breaths/ minute, and oxygen saturation of $82 \%$ on room air. The patient was placed on 4 liters oxygen per minute by nasal cannula (4L NC) and oxygen saturation increased to $94 \%$. Laboratory testing in the ED revealed a positive nasopharyngeal swab for SARS-CoV2 by polymerase chain reaction (PCR), white blood cells $5.6 \mathrm{k} / \mu \mathrm{L}$, hemoglobin $14.2 \mathrm{~g} / \mathrm{dL}$, platelets $141 \mathrm{k} / \mu \mathrm{L}$, troponin $29.5 \mathrm{ng} / \mathrm{L}$, lactate dehydrogenase 263 units/L, lactic acid $0.9 \mathrm{mmol} / \mathrm{L}$, and ferritin level $>2000 \mathrm{ng} / \mathrm{ml}$. A chest x-ray done on admission showed patchy bibasilar opacities. Computed tomography of the chest revealed multiple small areas of ground-glass opacities in both lungs. An electrocardiogram done in the ED did not demonstrate ischemic changes.
The findings on presentation were consistent with acute hypoxic respiratory failure secondary to pneumonia in the setting of confirmed SARS-CoV2 infection. The patient was admitted to the hospital's COVID-designated ward. Heparin was started for DVT prophylaxis at 5000 units SQ BID. Amoxicillin was discontinued, and she was started on ceftriaxone and azithromycin for empiric treatment of communityacquired pneumonia, which would also cover the concurrent strep pharyngitis. The patient had a left heart angiogram done recently, which revealed patent graft at that time. Although her troponin was initially elevated, it remained stable on subsequent testing throughout her hospitalization. Chest pain resolved upon oxygen supplementation in the ED. Supportive care continued with $4 \mathrm{~L}$ NC to maintain oxygen level above $90 \%$.

On hospital day 2, prednisone was stopped, and dexamethasone (6 mg daily) was started. Ceftriaxone and azithromycin were continued. Patient remained stable on 5L NC. On hospital day 3, mycophenolate mofetil and azithromycin were stopped. Azithromycin was discontinued due to supratherapeutic tacrolimus levels. Because of the elevated levels, tacrolimus dose was held on the evening of hospital day 3 and on the morning and evening of hospital day 4. On hospital day 5 , the patient received convalescent plasma. Attempts were made to decrease the oxygen supplementation but were not successful. On hospital day 8 , she became hypoxic and tachypneic with labored respirations. She was placed on a Venturi-mask at $50 \% \mathrm{FiO}_{2}$ and transferred to the Medical Intensive Care Unit for closer monitoring. She was also started on remdesivir IV and completed a five-day course. She received dexamethasone for a total of 10 days. Patient was transitioned to floor status on day 16 and was discharged on $3 \mathrm{~L} \mathrm{NC}$ from the hospital on day 17.

Throughout her 17-day hospitalization the patient maintained stable kidney function. The mycophenolate mofetil was held as part of the management of an active infection. Her tacrolimus regimen required multiple adjustments secondary to interactions with azithromycin and in an attempt to maintain serum trough levels around $6 \mathrm{ng} / \mathrm{ml}$ (Table 2). Prednisone was held after starting dexamethasone for 10 days as part of the COVID-19 management (Table 2) and then restarted at $5 \mathrm{mg}$ daily. 
Table 2. Oxygen and Medication Provided During Hospitalization

\begin{tabular}{|l|l|l|l|l|l|l|l|l|l|l|l|l|l|l|l|l|l|}
\hline & Day 1 & Day 2 & Day 3 & Day 4 & Day 5 & Day 6 & Day 7 & Day 8 & Day 9 & Day 10 & Day 11 & Day 12 & Day 13 & Day 14 & Day 15 & Day 16 & Day 17 \\
\hline Max. O 2 req./day & 5L NC & 5L NC & 5L NC & 5L NC & 5L NC & 5L NC & 5L NC & V mask & V mask & V mask & V mask & 4L NC & 4L NC & 4L NC & 4L NC & 3L NC & 3L NC \\
\hline $\begin{array}{l}\text { Immuno- } \\
\text { suppressants }\end{array}$ & P, M, T & P, M, T & T & none & T & T & T & T & T & T & T & T & T & T & T & T & T \\
\hline Dexamethasone & & x & $\mathrm{x}$ & $\mathrm{x}$ & $\mathrm{x}$ & $\mathrm{x}$ & $\mathrm{x}$ & $\mathrm{x}$ & $\mathrm{x}$ & $\mathrm{x}$ & $\mathrm{x}$ & & & & & \\
\hline Antibiotics & $\mathrm{A}, \mathrm{C}$ & $\mathrm{A}, \mathrm{C}$ & $\mathrm{C}$ & $\mathrm{C}$ & $\mathrm{C}$ & $\mathrm{C}$ & & & & & & & & & \\
\hline Remdesivir & & & & & & & & $\mathrm{x}$ & $\mathrm{x}$ & $\mathrm{x}$ & $\mathrm{x}$ & $\mathrm{x}$ & & & \\
\hline $\begin{array}{l}\text { Convalescent } \\
\text { Plasma }\end{array}$ & & & & & $\mathrm{x}$ & & & & & & & & & & \\
\hline Anticoagulation & $\mathrm{H}$ & $\mathrm{H}$ & $\mathrm{H}$ & $\mathrm{H}$ & $\mathrm{E}$ & $\mathrm{E}$ & $\mathrm{E}$ & $\mathrm{E}$ & $\mathrm{E}$ & $\mathrm{E}$ & $\mathrm{E}$ & $\mathrm{E}$ & $\mathrm{E}$ & $\mathrm{E}$ & $\mathrm{E}$ & $\mathrm{E}$ & $\mathrm{E}$ \\
\hline
\end{tabular}

$\mathrm{P}=$ prednisone, $\mathrm{M}=$ mycophenolate mofetil, $\mathrm{T}=$ Tacrolimus, $\mathrm{A}=$ azithromycin, $\mathrm{C}=$ ceftriaxone, $\mathrm{H}=$ heparin, $\mathrm{E}=$ Eliquis, Vmask $=$ Venti-Mask

\section{Discussion}

Although the patient still required oxygen therapy at discharge, she was continuing to improve and was expected to wean off oxygen. During this pandemic, evidence continues to be limited and controversial in regard to treatment of COVID-19 infection, especially in immunocompromised patients. This case report provides a data point demonstrating safety in the use of convalescent plasma, remdesivir, and dexamethasone in renal transplant patients infected with COVID19. It also supports the strategy of reducing chronic immunosuppression therapies when treating COVID19 in renal transplant patients, but more clinical studies are needed on the topic.

Article citation: Hannabas S, Hannabas G, Pena C. The use of convalescent plasma, dexamethasone and remdesivir in a renal transplant patient infected with COVID-19. The Southwest Respiratory and Critical Care Chronicles 2020;8(36):81-85

From: Departments of Internal Medicine (SH, CP) and Family Medicine $(\mathrm{GH})$, Texas Tech University Health Sciences Center, Lubbock, Texas

Submitted: $8 / 28 / 2020$

Accepted: 9/21/2020

Reviewer: Jacob Nichols MD

Conflicts of interest: none

This work is licensed under a Creative Commons

Attribution-ShareAlike 4.0 International License.

\section{REFERENCES}

1. Li L, Zhang W, Hu Y, et al. Effect of convalescent plasma therapy on time to clinical improvement in patients with severe and life-threatening COVID-19: A Randomized Clinical Trial. JAMA Aug 2020;324(5):460-470. doi:10.1001/jama.2020. 10044

2. Jiang J, Miao Y, Zhao Y, et al. Convalescent plasma therapy: Helpful treatment of COVID-19 in a kidney transplant recipient presenting with serve clinical manifestation and complex complications. Clin Transplant Jun 2020:e14025. doi:10.1111/ctr.14025

3. Zhu L, Xu X, Ma K, et al. Successful recovery of COVID19 pneumonia in a renal transplant recipient with long-term immunosuppression. Am J Transplant Jul 2020;20(7):18591863. doi:10.1111/ajt.15869

4. Beigel JH, Tomashek KM, Dodd LE. Remdesivir for the treatment of covid-19 - preliminary report. Reply. $N$ Engl J Med 09 2020;383(10):994. doi:10.1056/NEJMc2022236

5. Aslam S, Danziger-Isakov L, Luong M-L, et al. Guidance from the International Society of Heart and Lung Transplantation regarding the SARS CoV-2 pandemic. ISHLT; 2020. August 19, 2020.

6. Canadian Society of Transplantation and The Transplantation Society of Canada. Guidance on Coronavirus Disease 2019 (COVID-19) for Transplant Clinicians. TTS; 2020. https://tts.org/tid-about/tid-presidents-message/23-tid/ tid-news/657-tid-update-and-guidance-on-2019-novelcoronavirus-2019-ncov-for-transplant-id-clinicians

7. American Society of Transplantation. 2019-nCoV (Coronavirus): FAQs for Organ Transplantation. AST; 2020. https:// www.myast.org/sites/default/files/COVID19\%20FAQ\%20 Tx\%20Centers\%206.18.2020.pdf

8. Organ Procurement and Transplantation Network. Information for transplant programs and OPOs regarding 2019 Novel 
Coronavirus OPTN; 2020. https://optn.transplant.hrsa.gov/ news/information-for-transplant-programs-and-opos-regarding2019-novel-coronavirus/

9. EuropeanRenalAssociation/EuropeanDialysisandTransplantation Association. DESCARTES expert opinion regarding the management of immunosuppressive medication for kidney transplant patients during the COVID-19 pandemic. 2020. https://www.era-edta.org/en/wp-content/uploads/2020/04/ Expert-opinion-on-ISD-in-Covid-19.pdf

10. British Transplantation Society. Coronavirus: COVID-19 Information for transplant professionals 15th Edition, 14th August 2020. 2020. https://bts.org.uk/wp-content/uploads/ 2020/08/Coronavirus-transplant-information-15th-edition14th-August-2020.pdf 